\title{
Informational needs of general practitioners regarding discharge medication: content, timing and pharmacotherapeutic advices
}

\author{
Fatma Karapinar • Patricia M. L. A. van den Bemt • \\ Jan Zoer · Giel Nijpels · Sander D. Borgsteede
}

Received: 10 September 2009/Accepted: 26 December 2009/Published online: 14 January 2010

(C) The Author(s) 2010. This article is published with open access at Springerlink.com

\begin{abstract}
Objective To investigate the needs of Dutch general practitioners on discharge medication, both regarding content, timing and the appreciation of pharmacotherapeutic advices from clinical pharmacists. Setting A general teaching hospital in Amsterdam, the Netherlands. Method A prospective observational study was performed. A questionnaire with regard to the content, optimal timing (including way of information transfer) and appreciation of pharmacotherapeutic advices was posted to 464 general practitioners. One reminder was sent. Main outcome measure Description of the needs of general practitioners was assessed. For each question and categories of comments frequency tables were made. The Fisher-exact test was
\end{abstract}

F. Karapinar · J. Zoer · S. D. Borgsteede

Department of Hospital Pharmacy, Sint Lucas Andreas Hospital,

Amsterdam, The Netherlands

F. Karapinar · P. M. L. A. van den Bemt ( $)$

Division of Pharmacoepidemiology and Pharmacotherapy, Faculty of Science, Utrecht Institute for Pharmaceutical Sciences (UIPS), Utrecht University, PO Box 80082, 3508 TB Utrecht,

The Netherlands

e-mail: p.vandenbemt@uu.nl

P. M. L. A. van den Bemt

Department of Hospital Pharmacy, Erasmus Medical Center, PO Box 2040, 3000 CA Rotterdam, The Netherlands

G. Nijpels

Department of General Practice, EMGO Institute for Health and Care Research, VU University Medical Center, Amsterdam, The Netherlands

S. D. Borgsteede

Netherlands Pharmacovigilance Centre Lareb,

's-Hertogenbosch, The Netherlands used to study associations between the answers to the questions. Results In total, 149 general practitioners (32\%) responded. Most general practitioners (75\%) experienced a delay in receiving discharge medication information and preferred to receive this on the day of discharge. GPs wished to receive this information mainly through e-mail (44\%). There was a significant correlation $(P=0.002)$ between general practitioners who wanted to know whether and why medication had been stopped (87\%) and changed (88\%) during hospital admission. The general practitioners (88\%) appreciated pharmacotherapeutic advices from clinical pharmacists. Conclusion This study indicates how information transfer on discharge medication to GPs can be optimised in the Netherlands. The information arrives late and GPs want to be informed on the day of discharge mainly by e-mail. GPs wish to know why medication is changed or discontinued and appreciate pharmacotherapeutic advices from clinical pharmacists.

Keywords Continuity of care · Drug use · General practitioner - Hospital discharge . Interdisciplinary communication $\cdot$ Netherlands . Patient discharge

\section{Impact of findings on practice}

- Dutch general practitioners want to be informed on discharge medication on the day of discharge.

- Dutch general practitioners want information on reasons for changes and discontinuations of the pharmacotherapy and appreciate pharmacotherapeutic advices from clinical pharmacists.

- The exchange of information between hospital and general practitioners needs to be optimized. 


\section{Introduction}

Patients are often discharged from the hospital on drug therapy regimens different from those used before hospitalisation [1-3]. A recent study showed that in $98 \%$ of patients the pharmacotherapy was changed in hospital and in $60 \%$ of patients at least five changes were recorded [4]. These changes can be caused by for example alterations in disease state or the need for increased drug efficacy [1]. Medical care in chronic illness is moving increasingly from secondary to primary care [5]. The general practitioner (GP), who is responsible for the patient after discharge, must decide whether or not to maintain these changes, often without valid information with respect to the reasons for these changes [6].

At present information on medication is mainly transferred through discharge letters, which arrive relatively late and do not necessarily contain the information the GP needs. Studies have shown the possible consequences of inaccurate medication communication, for example the inappropriate restart of medication, that has been stopped during hospital admission due to adverse drug reactions [7, 8]. In order to improve the information transfer, policy documents outlining strategies to promote medication safety for patients moving from one care environment to another have been produced in the United Kingdom, the United States and recently in the Netherlands [9-11]. Implementing recommended strategies for safe medication transfer is likely to be more successful when these strategies match with the information needs of GPs. Limited (older) studies have focused on the information needs of GPs regarding discharge medication [1, 12-14]. However, the above mentioned policy documents [9-11] may have changed the need of GPs in recent years.

Additionally, in the policy documents the need for more cooperation between healthcare providers is discussed. In recent years clinical pharmacist have supported information transfer through checking for medication errors, counselling of the patient at hospital admission or discharge and provision of discharge medication lists to GPs [12, 15]. Clinical pharmacists seek for more collaboration with GPs as hospital physicians do not always feel responsible for the complete pharmacotherapy. However, it is unknown whether GPs appreciate pharmacotherapeutic advices from clinical pharmacists. Therefore, the aim of our study is to investigate the needs of GPs on discharge medication, both regarding content, timing (including way of information transfer) and appreciation of pharmacotherapeutic advices.

\section{Method}

Setting and study population

A prospective observational study was performed at the St. Lucas Andreas Hospital in Amsterdam, the Netherlands, a 550-bed general teaching hospital. An anonymous questionnaire was posted to all GPs within the catchment area of the hospital according to the hospital's information system ( $n=464)$ in July 2007. GPs could reply by mail or fax. In July and August questionnaires were received whereupon a reminder was sent in September 2007, allowing a response period of 2 months. The month of September was also chosen for sending the reminder, to enable family physicians to respond who were on holiday during the summertime. This study was exempt from review by the institutional review board, since the study concerned health care professionals and did not involve any intervention. The data were collected anonymously and stored in accordance with privacy regulations.

\section{Questionnaire and outcome}

In our hospital, in general, a provisional discharge letter is sent soon after hospitalization to inform the GP with a brief summary. In this provisional discharge letter the discharge medication should be mentioned. However, the discharge letter contains the ward-specific medication and not the complete list of medication the patient should be using. Information on which medication is changed or discontinued and reasons for this are generally not provided.

Therefore a questionnaire was designed to measure the needs of GPs concerning discharge medication with regard to the optimal timing, the optimal way of information transfer, content of information and appreciation of pharmacotherapeutic advices from clinical pharmacists. Examples of pharmacotherapeutic advices are: adding medication according to evidence-based guidelines (e.g. statin for secondary prevention in a patient with type 2 diabetes), discontinuation of not indicated preadmission used medication (e.g. iron tablets), monitoring compliance of a patient, therapeutic drug monitoring, or monitoring of electrolytes (e.g. potassium in patients using RAS-inhibitors) and kidney (mal)function (e.g. digoxin).

The questionnaire contained seven closed and one open question and was based on previous studies in primary care $[1,13,16]$. Topics were: delay in receiving information, the preferred time and way to receive this, requirement of information about changes or discontinuations in the pharmacotherapy, appreciation of pharmacotherapeutic advices and suggestions to improve the communication 
transfer. The GP was invited to comment on each question. The questionnaire was piloted on two persons. The revised questionnaire was posted to the GPs.

Data analysis

Analysis was performed with SPSS 14.0. For each question, frequency tables were made. The content of the open questions was qualitatively analysed, and three to six exclusive categories for each question were defined by FK and SDB. Each answer was classified in one of these categories and presented in frequency tables; differences in classification were solved by discussion. To study potential associations between the answers the Fisher-exact test was used.

\section{Results}

In total, 149 GPs (32\%) responded to the questionnaire, of whom $59(12 \%)$ responded after the reminder. The results of the questionnaire can be found in Table 1. Almost all GPs ( $n=143$ ) added one or more additional remarks/suggestions to the questions, which are described in detail in Table 2.

\section{Timing of information}

Most GPs (75\%) experienced a delay in receiving information about discharge medication and preferred to receive this on the day of discharge (see Table 1). Of the GPs that commented 55\% stated that they were confronted with questions of patients or family immediately after patient discharge and $26 \%$ wanted to arrange care activities after discharge. Twelve percent of GPs considered medication information essential to be responsible for the patient's medication (see Table 2). Some GPs (7\%) remarked that information was not needed instantly but could wait a few days as long as the patient was well informed and it was easy to contact the hospital.

\section{Content of information}

The GPs wanted to know whether and why medication had been stopped (87\%) and changed (88\%) during hospital admission. In their comments they explained that this information was important for educational purposes for themselves (38\%), to counsel the patient (29\%) and to prevent medication errors (14\%). Furthermore, one GP used this information to document any drug related problems in his computer system to prevent re-prescription of an inappropriate drug.

Pharmacotherapeutic advices

Most GPs (88\%) appreciated pharmacotherapeutic advices by clinical pharmacists concerning possible improvements
Table 1 GPs needs about the moment and content of information about medication prescribed at discharge $(n=149)$

\begin{tabular}{lcc}
\hline & Yes (\%) & No (\%) \\
\hline Moment of discharge medication information & & \\
Is there a delay in receiving information? & 75 & 25 \\
What is the preferred time to receive information? & \\
$\quad$ Day of discharge & 86 \\
$\quad$ Within some days of discharge & 7 \\
$\quad$ Other & 7 \\
Content of information & \\
Is information about changes in medication & \\
during hospital admission necessary? & \\
Yes, only what changes & 38 \\
Yes, both what changes and reasons for this & 3 \\
Not necessary & \\
Is information about stopped medication during & \\
hospital admission necessary? & \\
Yes, only what stops & 11 \\
Yes, both what stops and reasons for this & 87 \\
Not necessary & 2
\end{tabular}

on discharge medication. They remarked (38\%) that they could learn from these advices. GPs (38\%) further noticed that the implementation of a pharmacotherapeutic advice in individual patients should be a choice of the GP: there may be good reasons for not following the advice. Twelve percent of GPs did not want pharmacotherapeutic advices at all. Two GPs commented that improvements in the pharmacotherapy are the exclusive responsibility of the GP.

Method of information transfer and additional suggestions

GPs $(75 \%)$ didn't mind to receive the medication information separate from the discharge letter as long as the information was clear. The GPs $(25 \%)$ that did mind receiving a separate medication list commented that the GP 
Table 2 Comments of GPs on the questions $(n=143)$

\begin{tabular}{lr}
\hline Questions & $\mathrm{Nr}$ of comm \\
\hline What is the preferred time to receive information? & \\
Day of discharge & $42(100 \%)$ \\
Patient or family have questions & $23(55 \%)$ \\
To arrange care activities & $11(26 \%)$ \\
GP is responsible for medication after discharge & $5(12 \%)$ \\
Other reasons & $3(7 \%)$ \\
Within some days after discharge & $4(100 \%)$ \\
Patient or family have questions & $1(25 \%)$ \\
To arrange care activities & $1(25 \%)$ \\
If GP has questions he can contact the hospital & $1(25 \%)$ \\
As long as patient has been well informed & $1(25 \%)$ \\
Other & $3(100 \%)$ \\
Both options are possible as long as patient has been well informed & $2(67 \%)$ \\
Depends on the patient (co-morbidities) & $1(23 \%)$ \\
Is information about changes and discontinued medication & \\
during hospital admission necessary? & \\
Yes, both what changes or stops and reasons for this & $7(100 \%)$ \\
GP could possibly learn from it & $3(43 \%)$ \\
To answer questions of patients & $2(29 \%)$ \\
To check whether the adjustment are intentional & $2(28 \%)$ \\
to prevent re-prescription &
\end{tabular}

Are pharmacotherapeutic advices from hospital pharmacists about possible improvements appreciated?

$\begin{array}{lr}\text { Yes } & 8(100 \%) \\ \text { GP could possibly learn from it } & 3(38 \%) \\ \text { However implementation is a choice of GP } & 3(38 \%) \\ \text { However sometimes there are reasons for not prescribing a certain drug } & 2(24 \%) \\ \text { No } & 2(100 \%) \\ \text { Task and responsibility of GP } & \\ \text { Is it a problem to receive discharge prescriptions separate from the discharge letter? } \\ \text { Yes } & 8(100 \%) \\ \text { Not advisable as GPs have to search for the information } & 14(100 \%) \\ \text { No } & 5(36 \%) \\ \text { As long as the information is clear } & 5(36 \%) \\ \text { As long as GP receives information } & 4(28 \%) \\ \text { Other reasons } & 55(100 \%) \\ \text { Do you have further suggestions to improve the communication of medication } & \text { information? } \\ \text { Yes } & 17(31 \%) \\ \text { Clear and complete information regarding discharge medication is } & \\ \text { important (no handwritten forms, reason for changes provided etc.) } & 12(22 \%) \\ \text { Good initiative, further improvement is necessary } & 7(13 \%) \\ \text { Patient should also be informed with a medication list } & 5(9 \%) \\ \text { The right medication supply should be provided } & 5(9 \%) \\ \text { Substitution of medication in hospital should be prevented } & 2(4 \%) \\ \text { Consider cooperation with community pharmacy } & 7(12 \%) \\ \text { Other recommendations } & \end{array}$

should not have to search for the information. GPs wished to receive information regarding medication mainly through e-mail (44\%).
In their open suggestions, 55 GPs noted some suggestions for further improvements such as clear and complete discharge medication communication, informing the 
patient about discharge medication, providing the right medication supply to the patient, and substitution of medication in the hospital to the medication used outside the hospital.

\section{Association between answers}

There were no associations between the information transfer being delayed and the preferred time to receive the information, the information need about medication changes and discontinuations and the appreciation of pharmacotherapeutic advices (see Table 3 ). The wish to know which medication was changed was significantly correlated with the wish to know which medication was discontinued $(P=0.002)$. This was not correlated with the appreciation of pharmacotherapeutic advices.

\section{Discussion}

In our study $75 \%$ of GPs experienced a delay in receiving information about discharge medication and $86 \%$ preferred to receive this information on the day of discharge mainly because they were confronted with questions of patients and family immediately after patient discharge or wanted to arrange care activities after discharge. GPs wished to know why medication was changed $(88 \%)$ or discontinued ( $87 \%$ ) for educational purposes for themselves, to counsel the patient and to prevent medication errors. Most GPs $(88 \%)$ appreciated pharmacotherapeutic advices.

Changes in the pharmacotherapy during hospitalisation may cause adverse drug reactions and/or drug interactions at home [6]. Furthermore, reports have shown that many changes in drug therapy on transfer of care are due to medication errors [12, 13]. After being discharged from the hospital, patients often contact their GP [16]. The late or non-arrival of information and the failure to inform GPs about changes in the pharmacotherapy could lead to the continuation of medication errors in primary care $[1,2,5$, $6,13,17]$. Studies reported that $77-96 \%$ GPs want to know why medication is changed or discontinued, which is consistent with the results in our study [1, 13]. Only Munday et al. investigated in 1997 the reasons for these findings and they documented the same reasons as in our

Table 3 Association between provided answers

\begin{tabular}{|c|c|c|c|}
\hline \multirow[t]{2}{*}{ Questions } & \multicolumn{2}{|c|}{ Association with delay in information transfer } & \multirow[t]{2}{*}{$P$ value } \\
\hline & Yes & No & \\
\hline Preferred time to receive information & & & 0.774 \\
\hline Day of discharge & $92(75.4 \%)$ & $30(24.6 \%)$ & \\
\hline Days later & $13(72.2 \%)$ & $5(27.8 \%)$ & \\
\hline Information need about medication changes & & & 1.000 \\
\hline Changes (plus reasons) & $102(73.9 \%)$ & $36(26.1 \%)$ & \\
\hline Not important & $5(83.3 \%)$ & $1(16.7 \%)$ & \\
\hline Information need about medication discontinuations & & & 1.000 \\
\hline Discontinuations (plus reasons) & $103(75.2 \%)$ & $34(24.8 \%)$ & \\
\hline Not important & $2(66.7 \%)$ & $1(33.3 \%)$ & \\
\hline Appreciation of pharmacotherapeutic advices & & & 1.000 \\
\hline Yes & $87(74.4 \%)$ & $30(25.6 \%)$ & \\
\hline No & $13(76.5 \%)$ & $4(23.5 \%)$ & \\
\hline Discharge prescriptions separate from the discharge letter & & & 0.504 \\
\hline Yes & $27(79.4 \%)$ & $7(20.6 \%)$ & \\
\hline No & $75(72.8 \%)$ & $28(27.2 \%)$ & \\
\hline \multirow[t]{2}{*}{ Questions } & \multicolumn{2}{|c|}{ Association with information need about medication changes } & $P$ value \\
\hline & Yes & No & \\
\hline Information need about medication discontinuations & & & 0.002 \\
\hline Discontinuations (plus reasons) & $142(98.6 \%)$ & $2(1.4 \%)$ & \\
\hline Not important & $1(33.3 \%)$ & $2(66.7 \%)$ & \\
\hline Appreciation of pharmacotherapeutic advices & & & 0.512 \\
\hline Yes & $121(96.8 \%)$ & $4(3.2 \%)$ & \\
\hline No & $18(94.7 \%)$ & $1(5.3 \%)$ & \\
\hline
\end{tabular}


study, namely primarily to facilitate continuity of care, to inform the patient, to avoid the risks of adverse drug reactions, to eliminate prescribing errors and for educational purposes [1]. Himmel et al. showed that GPs received detailed information about drug changes in only five of the 130 hospital discharge letters showing the necessity for improvement [6]. These problems may have substantial implications for continuity of care and patient safety $[16,18]$. A recent study showed a trend toward a decreased risk of readmission within 3 months if patients were seen by a GP who had received a discharge letter (relative risk, 0.74; 95\% CI 0.05-1.10) [19].

Our study adds that the majority of GPs (88\%) appreciated pharmacotherapeutic advices by clinical pharmacists concerning possible improvements in the discharge medication. This provides collaboration possibilities between clinical pharmacist and general practitioners for example in situations where the hospital physician does not feel responsible for certain medication regimens (e.g. undertreatment), extra monitoring of medication is needed (e.g. kidney malfunction) or drug-related problems (e.g. compliance, side-effects) are identified. A recent study showed that GPs accepted advices and that these were well received because the advices provided new information, helped to better understand hospital recommendations and influenced prescribing [20]. It is important to recognise both the possible contribution of the clinical pharmacist to give a clinically relevant advice to optimise pharmacotherapy, as the responsibility of the GP to fit this advice in the individual drug therapy of the patient. Furthermore, the role of the community pharmacist within this process needs to be explored further.

There are several ways to inform GPs. In 1997 postal communication was preferred [1]. As nowadays more GPs have access to fax machines and electronic mail, these communication methods are preferred in our population.

In this study it seems that not only GPs who experience a delay in the information transfer wish to receive information on the day of discharge, as no significant association was identified between the answers to these questions. Furthermore, the delay in information transfer was not associated with the information need on medication changes, medication discontinuation and appreciation of pharmacotherapeutic advices implicating that this information was considered relevant anyway. The information need on medication changes and medication discontinuation was significantly correlated $(P=0.002)$ which is logical due to the relation of the two information types. However the information need on medication changes or discontinuations was not correlated with the appreciation of pharmacotherapeutic advices which implicates that different interventions can be developed to meet with the information needs of GPs.
Although this is one of the few studies clearly showing the informational needs of GPs, some limitations need to be discussed. First, the results reflect the findings in one geographical area, therefore limiting the generalizability of the results, although the results are comparable to the few other studies that have been conducted $[1,13,16]$.

Second, the response rate was relatively low, even though we sent a reminder. This may have led to selection bias, because only the GPs with a more positive attitude may have responded. Unfortunately, we were unable to investigate this bias because of the anonymity of the survey.

Notwithstanding these limitations, we believe that this questionnaire provides important insight in the needs of GPs concerning discharge medication.

Future studies should focus on implementing medication transfer systems tailored to GPs information needs and on the effect of implementing such systems on patient safety. Medicine management teams who reconcile medication, document changes and communicate this information to GPs have been described in literature [2]. Furthermore, future studies should also focus on how information regarding discharge medication can be transferred using standardized discharge letters. In the study of Van der Linden et al. it did not matter whether an adverse drug reaction was mentioned in the discharge letter or not for prevention of re-prescription of inappropriate drugs [7]. This implies that GPs probably did not notice the information on the adverse drug reaction. By designing future studies using a before-after design and studying clinically relevant endpoints (such as hospital readmissions), these studies will be able to contribute to our knowledge on the impact of implementing measures to improve the transfer of discharge medication to GPs. The results of the survey we have carried out, can aid in designing these measures for improvement of discharge medication transfer. Future interventions will reveal how sharing knowledge about optimal pharmacotherapy by an advice of the clinical pharmacist contributes to quality of pharmacotherapy.

\section{Conclusion}

This study indicates how information transfer on discharge medication can be optimised in the Netherlands. It shows that the information transfer to the GPs arrives late and that they want to be informed on the day of discharge mainly by e-mail. GPs wish to know why medication was changed or discontinued and appreciate pharmacotherapeutic advices from clinical pharmacists. For the further development of discharge interventions, these findings can be useful to design accurate discharge medication information sheets, organise timely transfer of information, and give 
pharmacotherapeutic advices to streamline the communication process between hospital and general practitioner.

Acknowledgement We would like to express our gratitude to the GPs who cooperated in this study. Also, we would like to thank $\mathrm{H}$. Wessemius (pharmaceutical consultant) and M. Mak and M. Wesselman (students) for the collection of data.

Funding No funding was received for this study.

Conflict of interest The authors declare no conflicts of interest.

Open Access This article is distributed under the terms of the Creative Commons Attribution Noncommercial License which permits any noncommercial use, distribution, and reproduction in any medium, provided the original author(s) and source are credited.

\section{References}

1. Munday A, Kelly B, Forrester JW, Timoney A, McGovern E. Do general practitioners and community pharmacists want information on the reasons for drug therapy changes implemented by secondary care? Br J Gen Pract. 1997;47(422):563-6.

2. Bellingham $\mathrm{C}$. How to improve medicines management at the primary secondary care interface. Pharm J. 2004;272:210-1.

3. Van der Kam WJ, Meyboom de Jong B, Tromp TF, Moorman PW, van der Lei J. Effects of electronic communication between the GP and the pharmacist. The quality of medication data on admission and after discharge. Fam Pract. 2001;18(6):605-9.

4. Grimmsmann T, Schwabe U, Himmel W. The influence of hospitalisation on drug prescription in primary care-a large-scale follow-up study. Eur J Clin Pharmacol. 2007;63(8):783-90.

5. Corry M, Bonner G, McEntee S, Dugan J, MacAuley D. Hospitals do not inform GPs about medication that should be monitored. Fam Pract. 2000;17(3):268-71.

6. Himmel W, Tabache M, Kochen MM. What happens to longterm medication when general practice patients are referred to hospital? Eur J Clin Pharmacol. 1996;50(4):253-7.

7. Van der Linden CM, Kerskes MC, Bijl AM, Maas HA, Egberts AC, Jansen PA. Represcription after adverse drug reaction in the elderly: a descriptive study. Arch Intern Med. 2006;166(15): 1666-7.

8. Zhang M, Holman CD, Preen DB, Brameld K. Repeat adverse drug reactions causing hospitalization in older Australians: a population-based longitudinal study 1980-2003. Br J Clin Pharmacol. 2007;63(2):163-70.

9. Smith J. Building a safer NHS for patients: improving medication safety: Department of Health (UK). http://www.dh.gov.uk/ prod_consum_dh/groups/dh_digitalassets/@dh/@en/documents/ digitalasset/dh_4084961.pdf (2004). Accessed 25 Nov 2009.

10. Joint Commission on Accreditation of Healthcare Organizations (JCAHO). National Patient Safety Goals, Goal 8 hospital version accurately and completely reconcile medications across the continuum of care. http://www.jointcommission.org/PatientSafety/ NationalPatientSafetyGoals/06_npsg_cah.htm (2006). Accessed 25 Nov 2009.

11. Concept policy document: transfer of information on medication [in dutch]. http://www.medicatieoverdracht.nl/uploaddb/downl_ object.asp?atoom $=9008 \&$ VolgNr=1. Accessed 25 Nov 2009.

12. Bolas H, Brookes K, Scott M, McElnay J. Evaluation of a hospital-based community liaison pharmacy service in Northern Ireland. Pharm World Sci. 2004;26(2):114-20.

13. Brookes K, Scott MG, McConnell JB. The benefits of a hospital based community services liaison pharmacist. Pharm World Sci. 2000;22(2):33-8.

14. Himmel W, Kron M, Hepe S, Kochen MM. Drug prescribing in hospital as experienced by general practitioners: East versus West Germany. Fam Pract. 1996;13(3):247-53.

15. Kaboli PJ, Hoth AB, McClimon BJ, Schnipper JL. Clinical pharmacists and inpatient medical care: a systematic review. Arch Intern Med. 2006;166(9):955-64.

16. Kripalani S, LeFevre F, Phillips CO, Williams MV, Basaviah P, Baker DW. Deficits in communication and information transfer between hospital-based and primary care physicians: implications for patient safety and continuity of care. JAMA. 2007;297(8): $831-41$.

17. Sexton J, Ho YJ, Green CF, Caldwell NA. Ensuring seamless care at hospital discharge: a national survey. J Clin Pharm Ther. 2000;25(5):385-93.

18. Morrison P, Abu-Arafeh I, Davison J, Chapman S. Optimum prescribing of discharge medicines: roles of hospital and community pharmacists. Pharm J. 2004;272(7287):224-7.

19. Van Walraven C, Seth R, Austin PC, Laupacis A. Effect of discharge summary availability during post-discharge visits on hospital readmission. J Gen Intern Med. 2002;17(3):186-92.

20. Kunz R, Wegscheider K, Guyatt G, Zielinski W, Rakowsky N, Donner-Banzhoff N, et al. Impact of short evidence summaries in discharge letters on adherence of practitioners to discharge medication. A cluster-randomised controlled trial. Qual Saf Health Care. 2007;16(6):456-61. 